\title{
NOTE
}

\section{Habitat bleaching disrupts threat responses and persistence in anemonefish}

\author{
Oona M. Lönnstedt ${ }^{1,2, *}$, Ashley J. Frisch ${ }^{1}$ \\ ${ }^{1}$ School of Marine and Tropical Biology and ARC Centre of Excellence for Coral Reef Studies, James Cook University, \\ Townsville, QLD 4811 Australia \\ ${ }^{2}$ Present address: Department of Ecology and Genetics, Limnology, Uppsala University, Uppsala, Sweden
}

\begin{abstract}
Climate-induced habitat bleaching is linked to dramatic declines in diversity and abundance of coral reef fish; however, mechanisms underlying these declines are poorly understood. Here, we used in situ studies to demonstrate that bleaching can influence persistence of reef fish by affecting behaviours, including responses to a potential predation threat. When encountering the predatory rock cod Cephalophalis cyanostigma, anemonefish Amphiprion akindynos occupying healthy unbleached host anemones Heteractis crispa respond by feeding less and spending more time within the anemone tentacles. When the host anemone was experimentally bleached, these visual risk responses were compromised: A. akindynos continued to feed and did not seek shelter. The impaired behavioural response may prove detrimental to anemonefish populations as abundance levels of fish on bleached anemones was reduced by $60 \%$ within $3 \mathrm{~d}$, which may have been the result of increased predation. Our data illustrate how climate-induced habitat degradation can drive declines of reef fish by potentially altering outcomes of predatorprey interactions.
\end{abstract}

KEY WORDS: Climate change $\cdot$ Habitat degradation $\cdot$ Zooxanthellae $\cdot$ Great Barrier Reef $\cdot$ Risk assessment

Resale or republication not permitted without written consent of the publisher

\section{INTRODUCTION}

Marine systems worldwide are subjected to numerous stressors including elevated temperatures, changing ocean currents and an increase in the prevalence of severe storms, which have all led to a decline in the state of coastal marine communities (Graham et al. 2006, Hughes et al. 2007). Impacts on tropical coral reefs have received considerable attention; here effects often manifest as acute and pervasive mass bleaching events (Donner et al. 2005). This is caused by sustained thermal stress which forces reef-building cnidarians to expel their symbiotic dinoflagellates (zooxanthellae, a source of energy and pigmentation), leaving only the clear tissue and bright white skeleton behind (Siebeck et al. 2006, Anthony et al. 2007). Studies have documented sig- nificant and widespread declines in coral-dwelling fish following bleaching events (Booth \& Beretta 2002, Pratchett et al. 2008), but the underlying mechanisms through which fish abundance and diversity are affected are poorly understood. Organisms likely to be particularly vulnerable to bleaching include specialist species or those that depend on their habitat for food, protection or dispersal (Parmesan 2006).

Anemonefish (damselfish family, Pomacentridae) comprise 30 recognised species, all obligately associated with anemones (Ollerton et al. 2007). Anemonefish avoid predators by sheltering among the stinging tentacles of host anemones, therefore displaying a high level of habitat dependence (Fautin \& Allen 1997). Since anemones rely on zooxanthellae for up to $85 \%$ of their nutrient budget, warming temperatures and subsequent bleaching events are expected 
to have severe consequences for anemone survival, also affecting the animals that rely on them (SaenzAgudelo et al. 2011). Indeed, studies have documented dramatic reductions in the abundance of anemonefish following bleaching events (Jones et al. 2008, Hobbs et al. 2013), but whether individuals move to alternate habitats or succumb to increased mortality from predation remains unknown. Although some studies have suggested that habitat degradation makes juvenile reef fish more vulnerable to predators by impairing chemosensory responses (Lönnstedt et al. 2014) and/or reducing fish camouflage (Coker et al. 2009, McCormick 2009), no study has experimentally tested how visual risk responses of specialist species are affected by habitat stressors such as bleaching.

Here, we examined immediate effects of anemone bleaching on behaviour and persistence of a common anemone-dwelling fish, Amphiprion akindynos, in its natural environment. We experimentally manipulated in situ bleaching of its host anemone, Heteractis crispa, and investigated how bleaching affected responses of fish to a potential threat, the common predatory rock cod Cephalophalis cyanostigma. Fish on host anemones were initially tested for a behavioural response to the sight of the predator (placed in a watertight bag). Fish were then left on the anemone, or were removed while the anemone was either placed under a temporary cage or was experimentally bleached. After anemone manipulation, fish were returned to their original host anemone, their behaviour and threat response were re-assessed, and their persistence was monitored for $72 \mathrm{~h}$. This is the first time, under natural conditions, that the consequences of habitat bleaching on anemonefish behaviour and persistence have been tested.

\section{MATERIALS AND METHODS}

\section{Test species}

Experiments were conducted in April and May 2013 on the fringing reefs surrounding Northwest Island $\left(23.2965^{\circ} \mathrm{S}, 151.7075^{\circ} \mathrm{E}\right)$ on the southern Great Barrier Reef, Australia. Our test species was the Great Barrier Reef anemonefish Amphiprion akindynos, which is a common tropical anemonefish with a broad Indo-Pacific distribution that preferentially inhabits anemone colonies of the Sebae anemone Heteractis crispa (Fautin \& Allen 1997). Adult fish are site attached, rarely move between anemones and are vulnerable to ambush predators. Sev- eral A. akindynos live together in a social group within a single anemone. The female is the largest member, and there are usually up to 5 males sharing the anemone with her. The dominant male is the second largest member of the group and the reproductive mate of the female. A pilot study showed that behaviours of the largest male were representative of remaining colony members; hence it was chosen as the focal individual to maintain consistency among trials.

\section{Experimental procedure}

Together with their anemone host H. crispa, 30 naturally occurring colonies of $A$. akindynos (2 to 6 members) were located in the wild. Healthy anemones with equal numbers of colony members were then randomly assigned to 1 of 3 treatments ( $\mathrm{n}=10$ anemone colonies per treatment): (1) treatment control, (2) disturbance control or (3) experimental bleaching. The experiment was divided into 2 stages. First (initial stage), we examined the behaviour of focal males across the 30 anemone colonies. Following observations, fish in treatment controls were left undisturbed on the reef while all group members in Treatment 2 (controlling for the effect of removing and returning fish to the reef) and Treatment 3 (experimental bleaching) were caught. Fish were caught using a dilute clove oil anaesthetic and a fence net and brought back to the laboratory while host anemones were experimentally bleached or caged (to ensure host anemones were protected from coelenterate predators during fish removal). Group members from the same anemone were kept together in well-aerated seawater aquaria $(20 \times 15 \times 30 \mathrm{~cm})$ with a coral shelter and a $2 \mathrm{~cm}$ layer of sand covering the bottom. To minimise stress, holding tanks were covered with shade cloth and fish were fed ad libitum twice daily. After 13 d (return stage), the black plastic covering bleached anemones and wire net cages covering disturbance control anemones were removed and all fish were returned to host anemones. Upon return, a mesh cage was placed on top of the anemone for 1 to $2 \mathrm{~h}$. The mesh was large enough to allow fish to swim out, but not large enough to allow predators to reach them, allowing fish to recover from the stress of handling ( $100 \%$ remained on anemones during this time). After the acclimation period, the cage was removed and focal fish from each of the 30 anemone colonies had their behaviour reassessed. 


\section{Behaviour and survival assay}

Behaviours and threat responses were recorded at the initial stage and return stage across the 3 treatments. Behavioural observations followed wellestablished protocols (McCormick 2009, Lönnstedt et al. 2012, 2014) and consisted of a 3 min pre-stimulus presentation period followed by a $3 \mathrm{~min}$ post-stimulus presentation period. Behaviour of the largest male fish (size: $5.4 \pm 0.49 \mathrm{~cm}$, mean standard length $[\mathrm{SL}] \pm \mathrm{SE}$ ) was conducted by a SCUBA diver situated $2 \mathrm{~m}$ away from the patch reef. Following the $3 \mathrm{~min}$ pre-stimulus period, fish were exposed to a potential threat, the predatory rock cod Cephalophalis cyanostigma (size: $10.9 \pm 0.56 \mathrm{~cm}$ SL) which was placed inside a transparent plastic bag containing seawater (e.g. Lönnstedt et al. 2012). The bag was attached to the end of a $1.5 \mathrm{~m}$ pole that was slowly juxtaposed with the anemone and behaviours of the focal animal were observed for a further $3 \mathrm{~min}$. The rock cod is a larger piscivorous reef fish known to feed on damselfish individuals and hence should represent a predation threat to A. akindynos (Bosiger et al. 2012). During each observation period, we collected data on (1) bite rate, measured as successful and unsuccessful feeding strikes, (2) maximum distance $(\mathrm{cm})$ from the anemone, and (3) total amount of time (s) spent inside the tentacles of the anemone.

Following the return stage, individual survival (persistence) of all group members on the 30 different $H$. crispa colonies was monitored twice a day for $72 \mathrm{~h}$ after release. Divers returned to anemones and carefully noted the number of colony members left on the anemone. Previous tagging studies suggest that migration between habitats in damselfish returned to the reef is negligible (McCormick 2009, McCormick \& Meekan 2010), but to further account for dispersal effects, divers monitoring fish survival thoroughly searched the area around individual anemone colonies for vagrant anemonefish (none were found). Furthermore, on 2 separate occasions, fish displaying risky behaviours when returned to bleached anemones were observed being consumed by predators. Therefore, when fish were missing, they were assumed to have been caught by predators. However, the authors note that survival results should be interpreted with caution.

\section{Anemone bleaching}

The process of bleaching involves the expulsion of symbiotic zooxanthellae algae when the ane- mone is under stress. This can happen when water temperatures reach $>1^{\circ} \mathrm{C}$ above the summer maximum but also when anemones are deprived of direct sunlight (Anthony et al. 2007). Following fish removal, H. crispa colonies were covered with a thick black plastic sheet $(60 \times 60 \mathrm{~cm})$. Sheet size was then adjusted to match the size of the anemone colony. The sheets were weighed down with 4 dive weights (2 kg, 1 in each corner), and the coverage of the entire anemone was ensured. We used this method of bleaching as it allowed us to induce bleaching in situ relatively rapidly, while anemones still produced similar signs and symptoms as those put under thermal stress (A. Frisch unpubl. data). The plastic sheets were checked every other day, and bleaching progress was monitored using the coral health chart developed by Siebeck et al. (2006). Anemone colour (a good indication of the state of bleaching) was monitored twice daily until it reached the penultimate stage of bleaching, when it was monitored daily. It took up to $13 \mathrm{~d}$ for all anemone colonies to completely bleach with the light deprivation method.

\section{Statistical analysis}

Fish behaviours (pre-stimulus) and threat responses (post - pre) in the 3 experimental treatments at the initial and return stage were compared using MANOVA, given the interdependency of the 3 variables: bite rate, maximum distance from anemone $(\mathrm{cm})$, and time spent within anemone tentacles (s). Significant effects were further investigated using ANOVAs. Assumptions of homogeneity of variance and normality were examined with residual analysis. Maximum distance from anemone did not follow parametric assumptions and was $\log _{10}(x+1)$-transformed. Survival (up to $72 \mathrm{~h}$ ) of fish on the 2 different habitat types was compared using multiple-sample survival analysis with a Cox's proportional hazard model. Persistence curves of fish from the 3 treatments were calculated and plotted using the KaplanMeier product-limit method.

\section{RESULTS}

Initial stage behaviours did not differ between treatments (MANOVA, $F_{6,50}=0.66, \mathrm{p}=0.68$ ). However, return stage behaviours differed significantly in all variables between treatments (MANOVA, $F_{6,50}=$ $6.08, \mathrm{p}<0.0001)$. Fish returned to bleached ane- 
mones fed less (ANOVA, $F_{2,26}=13.18, \mathrm{p}=0.0001$; Fig. 1a), ventured further from shelter (ANOVA, $F_{2,26}=4.96, \mathrm{p}=0.014$; Fig. $1 \mathrm{~b}$ ) and spent significantly less time inside the protection of the anemone tentacles (ANOVA, $F_{2,26}=6.53, \mathrm{p}=0.005$; Fig. $1 \mathrm{c}$ ) than fish returned to healthy anemones (disturbance controls) or those fish left on host anemones and re-tested after $13 \mathrm{~d}$ (treatment controls).

There was no significant difference in threat responses of anemonefish between the 3 treatments at the initial stage (MANOVA, $F_{6,50}=0.234, \mathrm{p}=0.69$ ). However, at the return stage there was a strong influence of anemone treatment on visual risk assessment behaviours (MANOVA, $F_{6,50}=9.376, \mathrm{p}<0.0001$; Fig. 1d-f). ANOVAs showed that there were significant differences in foraging rate $\left(F_{2,26}=52.49, \mathrm{p}<\right.$ 0.0001 ; Fig. 1d), maximum distance ventured $\left(F_{2,26}=\right.$ 6.973, p = 0.0038; Fig. 1e) and time spent inside the anemone $\left(F_{2,26}=56.36, \mathrm{p}<0.0001\right.$; Fig. 1f $)$ when exposed to predators depending on whether fish where found on bleached or healthy anemones. Amphiprion akindynos returned to bleached anemones did not reduce foraging levels or spend more time inside the anemone when exposed to a predation threat (Fig. 1d-f).

Persistence (disappearance rates) of anemonefish was also significantly affected by the state of its host anemone $\left(\chi_{2}^{2}=17.16, p=0.0002\right.$; Fig. 2). Fish persistence split into 2 groups, with anemonefish returned to unbleached host anemones (disturbance controls) and those left undisturbed on healthy anemones in the field (treatment controls) showing a high and similar persistence (16 to $20 \%$ of anemonefish were missing within $72 \mathrm{~h}$ after release) compared to anemonefish returned to bleached host anemones, which displayed significantly higher losses (60\% of fish were absent within $72 \mathrm{~h}$ after release).

\section{DISCUSSION}

The present study is the first to examine effects of habitat bleaching on risk assessment behaviours and individual persistence in naturally occurring populations of anemonefish. Anemone bleaching was found to disrupt the innate threat responses normally seen
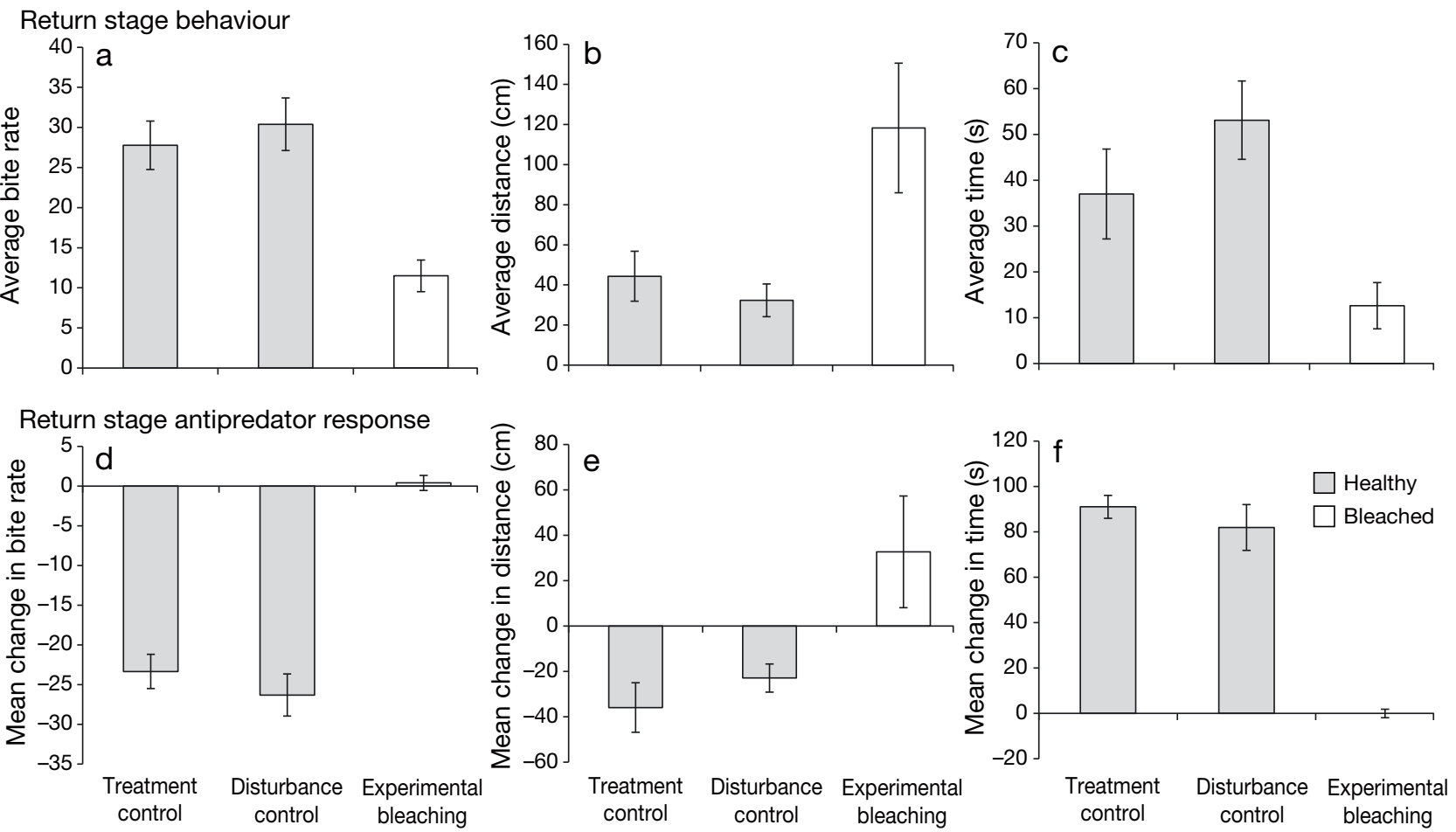

Fig. 1. Anemone health affects behaviours and threat responses of Amphiprion akindynos at the return stage ( $\mathrm{n}=10)$. The top row (a-c) shows average (a) bite rate (number of feeding strikes made during a 3 min observation period), (b) maximum distance from anemone Heteractis crispa $(\mathrm{cm})$, and (c) total time spent inside the shelter of the anemone tentacles (seconds) displayed by anemonefish in the 3 different treatments. The bottom row $(d-f)$ shows the mean behavioural change in (d) bite rate, (e) maximum distance from the anemone ( $\mathrm{cm}$ ), and (f) time spent inside the host anemone (s) when fish were exposed to a predatory rock cod Cephalophalis cyanostigma in healthy (treatment controls and disturbance controls) and bleached anemones 


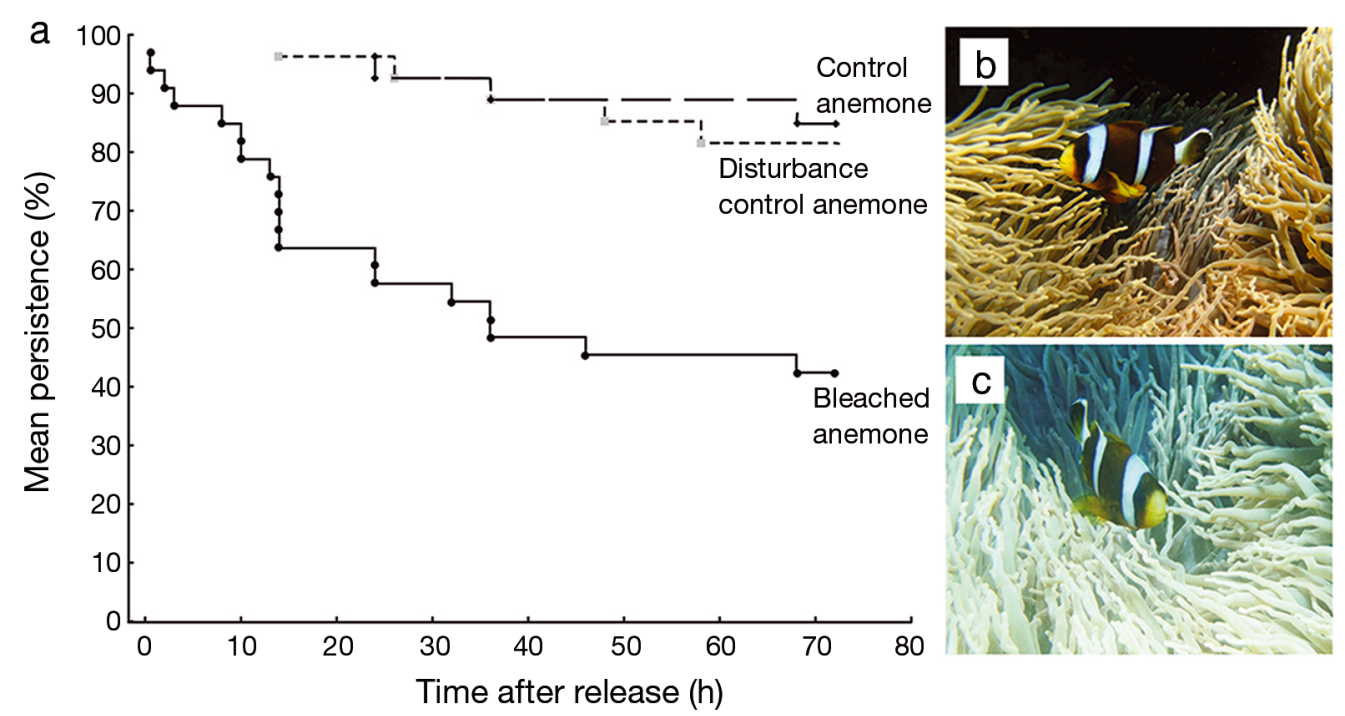

Fig. 2. (a) Persistence curves (Kaplan-Meier plot) of Amphiprion akindynos placed on either (b) healthy (control or disturbance control) or (c) bleached anemones Heteractis crispa. Anemonefish had their persistence monitored for $72 \mathrm{~h}$

in Amphiprion akindynos. Furthermore, data suggest that altered threat responses were associated with lower survival, as abundance of fish on bleached anemones was reduced by $\sim 70 \%$ compared to that on healthy unbleached anemones. In nature, bleaching events are only expected to become more frequent and severe (Donner et al. 2005, Hughes et al. 2007), and increased mortality (disappearance) of the scale detected here could seriously threaten anemonefish populations.

To understand the wider effects of habitat degradation on reef fish communities, we must identify underlying behavioural process that may be driving observed declines in the abundance of many prey fish (Jones et al. 2008, Lönnstedt et al. 2014). In the clear water world of coral reefs, life and death due to predation often revolve around good vision, and if the visual threat response is impaired by habitat bleaching, there could be severe consequences for risk assessment abilities and survival (Lönnstedt et al. 2012). Indeed, current results suggest that habitat bleaching affected responses to a potential threat, as A. akindynos responded to a piscivorous rock cod with reduced foraging and increased shelter use in healthy, unbleached anemones but either failed to detect or ignored Cephalophalis cyanostigma in bleached habitats.

During bleaching the symbiotic zooxanthellae within the anemones die, become necrotic and are expelled (Siebeck et al. 2006), which may leave an olfactory signal that could be detected by fish. If bleached anemones give off necrotic smells that are repugnant, fish inhabitants may be unwilling to retreat back into their stressed hosts even in the presence of predators. Previous studies have suggested the smell of dying tissue may force individuals away from bleached habitats, with the switch from conservative to risky behaviours leading to higher vulnerability (Coker et al. 2009, McCormick 2009). Alternatively, the bright white background of the bleached habitats may deceive prey individuals into distancing themselves from the monochrome white anemone in an attempt to improve camouflage (Marshall et al. 2003). Then again, brightly coloured fish may immediately become more susceptible to predation due to the increased perception of individuals against the stark white background of bleached habitats. Regardless of the underlying mechanism, fish in bleached habitats did not display threat responses when exposed to C. cyanostigma. This was coincident with lower persistence that may well have resulted from increased predation (e.g. Booth \& Beretta 2002).

In the current study, we show that climateinduced habitat change poses several problems for reef fish that display obligate habitat associations. In bleached anemones, A. akindynos individuals displayed altered behaviours and significant and rapid abundance declines. The specific reasons for these declines are poorly understood and probably varied, but our findings provide a mechanism through which habitat degradation may be impacting anemonefish survival. If the impairment of threat responses in bleached habitats translates to 
higher mortality as a result of increased predation risk, there could be severe consequences for the future of these iconic and commercially valuable coral reef fishes.

Acknowledgements. We thank M. Finn, S. Frisch and Mrs. Brown for logistic support in the field and P. Osmond for supplying us with an unsinkable vessel. Fieldwork and research was funded by the ARC Centre of Excellence and the James Cook University Graduate Research Scheme. Behavioural experiments were conducted in accordance with animal ethics guidelines at James Cook University and the Great Barrier Reef Marine Park Authority (Ethics permit A1593, GBRMPA permit G12/ 34941.1). A research permit from the Great Barrier Reef Marine Park Authority allowed us to bleach 10 anemones (No. G13/35980.1).

\section{LITERATURE CITED}

Anthony KRN, Connolly SR, Hoegh-Guldberg O (2007) Bleaching, energetics, and coral mortality risk: effects of temperature, light, and sediment regime. Limnol Oceanogr 52:716-726

Booth DJ, Beretta GA (2002) Changes in a fish assemblage after a coral bleaching event. Mar Ecol Prog Ser 245: 205-212

Bosiger YJ, Lönnstedt OM, McCormick MI, Ferrari MCO (2012) Learning temporal patterns of risk in a predatordiverse environment. PLoS ONE 7:e34535

Coker DJ, Pratchett MS, Munday PL (2009) Coral bleaching and habitat degradation increase susceptibility to predation for coral-dwelling fishes. Behav Ecol 20: $1204-1210$

Donner SD, Skirving WJ, Little CM, Oppenhemier M, Hoegh-Guldberg O (2005) Global assessment of coral bleaching and required rates of adaptation under climate change. Glob Change Biol 11:2251-2265

Fautin DG, Allen GR (1997) Anemonefishes and their host sea anemones. Western Australian Museum, Perth

Graham NA, Wilson SK, Jennings S, Polunin NV, Bijoux JP, Robinson J (2006) Dynamic fragility of oceanic coral reef ecosystems. Proc Natl Acad Sci USA 103:8425-8429

Editorial responsibility: Ivan Nagelkerken,

Adelaide, South Australia, Australia
Hobbs JPA, Frisch AJ, Ford BJ, Thums M, Saenz-Agudelo P, Furby KA, Berumen ML (2013) Taxonomic, spatial and temporal patterns of bleaching in anemones inhabited by anemonfishes. PLoS ONE 8:e70966

> Hughes TP, Rodrigues MJ, Bellwood DR, Ceccarelli D and others (2007) Phase shifts, herbivory, and the resilience of coral reefs to climate change. Curr Biol 17:360-365

Jones AM, Gardner S, Sinclair W (2008) Losing 'Nemo': bleaching and collection appear to reduce inshore populations of anemonefishes. J Fish Biol 73:753-761

Lönnstedt OM, McCormick MI, Meekan MG, Ferrari MCO, Chivers DP (2012) Learn and live: predator experience and feeding history determines prey behaviour and survival. Proc R Soc Lond B Biol Sci 279:2091-2098

> Lönnstedt OM, McCormick MI, Chivers DP, Ferrari MCO (2014) Habitat degradation is threatening reef replenishment by making fish fearless. J Anim Ecol 83:1178-1185

- Marshall NJ, Jennings K, McFarland WN, Loew ER, Losey GS (2003) Visual biology of Hawaiian coral reef fishes: III. Environmental light and an integrated approach to the ecology of reef fish vision. Copeia 2003:467-480

> McCormick MI (2009) Behaviourally mediated phenotypic selection in a disturbed coral reef environment. PLoS ONE 4:e7096

> McCormick MI, Meekan MG (2010) The importance of attitude: the influence of behaviour on survival at an ontogenetic boundary. Mar Ecol Prog Ser 407:173-185

> Ollerton J, McCollin D, Fautin DG, Allen GR (2007) Finding NEMO: nestedness engendered by mutualistic organization in anemonefish and their hosts. Proc R Soc Lond B Biol Sci 274:591-598

> Parmesan C (2006) Ecological and evolutionary responses to recent climate change. Annu Rev Ecol Evol Syst 37: 637-666

Pratchett MS, Munday PL, Wilson SK (2008) Effects of climate-induced coral bleaching on coral reef fishes: a review of ecological and economic consequences. Oceanogr Mar Biol Annu Rev 34:251-296

Saenz-Agudelo P, Jones GP, Thorrold SR, Planes S (2011) Detrimental effects of host anemone bleaching on anemonefish populations. Coral Reefs 30:497-506

Siebeck UE, Marshall NJ, Klüter A, Hoegh-Guldberg O (2006) Monitoring coral bleaching using a colour reference card. Coral Reefs 25:453-460

Submitted: February 17, 2014; Accepted: September 6, 2014 Proofs received from author(s): December 2, 2014 